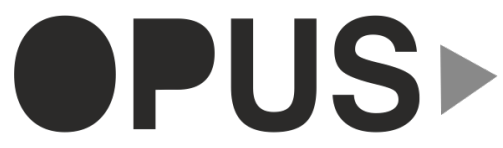

Uluslararası Toplum Araştırmaları Dergisi International Journal of Society Researches
E-ISSN : 2528-9535

YIl Year: 9

Cilt Volume: 14

Sayı Issue :20

Aralık December 2019

Makalenin Gelis Tarihi Received Date: 10/07/2019

Makalenin Kabul Tarihi Accepted Date: 21/11/2019

\title{
Türkiye'de Özgüven ile İlgili Yapılan Lisansüstü Tezlerin İncelenmesi
}

\author{
DOI: $10.26466 /$ opus.590461
}

*

\author{
Okan Bilgin * \\ * Dr. Öğr. Üy., Zonguldak Bulent Ecevit Üniversitesi, Eğitim Fakültesi, Ereğli/Zonguldak /Türkiye \\ E-Posta: bilgin.okan@gmail.com \\ ORCID: $\underline{0000-0001-6233-4290}$
}

\section{Öz}

Doğuştan getirilmeyen özgüven birey yaşadıkça şekillenmekte ve sahip olunan özgüven düzeyi yaşamin her anında bireyi olumlu ya da olumsuz olarak etkilemektedir. Yüksek özgüven düzeyinin bireye birçok farklı alanda sağladığ yararlar olmakla birlikte düşük özgüven düzeyine sahip bireylerin birçok alanda problem yaşadığı görülmektedir. Bu nedenle özgüven ile ilgili yapılan çalışmaların incelenmesi önemlidir. Bu çalı̧̧manın amacı, Türkiye'de özgüven ile ilgili yapılmış lisansüstü tezlerin incelenmesidir. Doküman analizi yöntemi kullanılan araştırmanın örneklemini, YÖK Yayın Dokümantasyon Daire Başkanlı̆̆̆ tarafından arşivlenen, konu bölümü özgüven olarak dizginlenen 91 lisansüstü eğitim tezi oluşturmaktadır. Yapılan çalışmaların incelenmesi sonucunda özellikle 2012 yılından sonra özgüven ile ilgili yapılan yüksek lisans tezlerinde ciddi bir artış olduğu, çalışmaların çoğunluğunun sosyal bilimler ve eğitim bilimleri alanında yapıldığı bulunmuştur. Yayınlarda örneklem olarak en çok yetişkinler ve üniversite öğrencileri ile çalışıldığg görülmüştür. Çalışmaların büyük bir kısmında nicel araştırma desenine yer verildiği ve bu doğrultuda en çok kullanılan yöntemin tarama yöntemi olduğu belirlenmiştir. Veri analiz tekniklerinde ise ANOVA, korelasyon ve t-testinin en fazla kullanılan istatistik teknikleri olduğu bulunmuştur. Son olarak özgüven ile birlikte çalışılan kavramlar incelendiğinde özgüvenin ă̆ırlıklı olarak eğitim-öğretim, aile, spor ve sanat konu alanları ile çalışıldığı tespit edilmiştir. .

Anahtar Kelimeler: Özgüven, Lisansüstü, İçerik analizi 


\title{
Investigation of the Postgraduate Theses Performed on Self-Confidence in Turkey
}

*

\begin{abstract}
Self-confidence continues to develop as long as an individual lives and the level of self-confidence affects the individual positively or negatively in every moment of life. Although the high level of selfconfidence provides benefits to the individual in many different areas, it is seen that individuals with low self-confidence experience problems in many areas. Therefore, it is important to examine the studies about self-confidence. The aim of this study was to investigate self-confidence of related postgraduate theses made in Turkey. Document analysis method was used in the research. The sample of the research consisted of 91 postgraduate theses, archived by Department of Higher Education Publication Documentation, restrained as self-confidence. As a result of the study, it was found that there was a significant increase especially in master theses about self-confidence after 2012, and most of the studies were conducted in the field of social sciences and educational sciences. In the theses, it was determined that adults and university students mostly worked as samples. Quantitative research design was used in most of the studies and it was revealed that the most commonly used method was the survey method. In data analysis techniques, ANOVA, correlation and $t$-test were the most commonly used statistical techniques. Finally, when the concepts studied with self-confidence were examined, it was found that self-confidence was mainly focused on the fields of education, family, sports and arts.
\end{abstract}

Keywords: Self-confidence, Postgraduate, Content analysis 


\section{Giriş}

Bireyin kendi değeri konusunda ki öznel bir yarg1sı olan özgüven (Kasatura, 1998) doğuştan getirilen kalıtsal bir özellik değildir. Birey yaşadıkça şekillenen özgüvenin temelleri bebeklik döneminde kazanılan güvengüvensizlik duygusu ile atılmaya başlanır (Göknar, 2010). Kişilerarası ilişkileri etkileyen en önemli duygu olan güven duygusu psikolojik olarak sağlıklı olmanın temel ön koşullarından birisidir (Eldeleklioğlu, 2004; Arslan, 2008). İnsan yaşamının her anını etkileyen özgüvenin oluşumu temelleri 0-2 yaşında atılan temel güven duygusunun kazanılmasına bağlıdır. Bireyin kendini tanıması, kendini sevmesi, yetenek ve duygularının farkında olarak yapabileceklerine inanması olarak tanımlanan özgüven (Altıntaş, 2015) statik değildir ve bebeklikten başlayarak hayat boyu gelişmeye devam eder (Özbey, 2004; Lauster, 2010). İnsan yaşam1 için çok önemli olan özgüven bireyin istediklerini yapabilmeleri için hareket etmeleri ve o doğrultuda davranmaları için itici bir güçtür. Bandura (1997)'ya göre özgüven kişinin kendini değerli hissetme yargısıdır. Hambly (2003) özgüveni bireyin kendi yeteneklerine olan inanc1, yüreklilik ve cesaret olarak tanımlamaktadır. En genel tanımı ile özgüven, insanın kendi yapabileceklerine duyduğu güven ve kendisini sevme kapasitesidir (Sar1, 2016). Bireyin kendini tanıması, kendini sevmesi, kendini olduğu gibi kabul etmesi, değerinin farkına varması, kendini ve olayları kontrol edebileceği inancı (Eldeleklioğlu, 2004) gibi durumlarla ilgili olan özgüvenin yüksek veya düşük olması bireyin yaşamını şekillendirmektedir. Bir kişinin sahip olduğu özgüven düzeyi onun istediği yaşamı elde etmesi için itici bir güç olacağından iyi bir özgüven ile insanlar kendi eylemlerinin ve yaşamlarının seyrini de belirleyebilmektedir (Karamoy, Wibowa ve Jafar, 2018).

Bireyin kendini değerlendirmesi sonucu oluşan ve öznel bir olgu olan özgüven, yüksek, düşük veya orta düzeyde olabilir. Bireyin özgüven düzeyi ise onun duygu ve davranışlarını farklı yönlerde etkileyebilmektedir (Soner, 1995). Düşük özgüvene sahip insanlar kendilerini genellikle geri planda tutarlar. Bu insanların değersiz olduklarına olan inancı çok kuvvetlidir ve risk alma konusunda cesaretsizdirler. Özerk davranabilme noktasında başarılı olamayan düşük özgüven düzeyine sahip bireyler genellikle başkalarına bağımlı olarak yaşarlar (Başoğlu, 2007). Olum- 
lu ve olumsuz deneyimlerin karışımına sahip olan özgüven düzeyi orta olan kişiler ise zaman zaman kendi deneyimlerine güvenip özerk davransalar dahi çoğu zaman özerk olamazlar (Humphreys, 2002). Hata yapma riskini göze alarak yeni deneyimlerde bulunmayı fırsat bilen ve kişilerarası ilişkileri kuvvetli olan yüksek özgüven düzeyine sahip bireyler ise hayatı bir denge içinde yaşayarak kendilerini ve başkalarını olduğu gibi kabul ederler (Altıntaş, 2015).

Yüksek özgüven düzeyine sahip olmanın bireye getirdiği avantajlar yapılan çalışmalar sonucunda da ortaya konulmaktadır. Literatür incelendiğinde özgüvenin; psikolojik dayanıklılık (Akkuş, 2015), güdülenme (Toktaş, 2017), benlik saygısı ve liderlik (Erpalabıyık, 2018), öfke kontrolü (Dursun, 2018), beden algıları (Ayna, 2019), kriz yönetimi ve karar verme (Atılgan, 2018), affedicilik (Aslan, 2016), kişisel gelişim inisiyatifi alma becerisi (Okyay, 2012), aile uyumu ve akademik başarı (Soner, 1995), özyeterlik algıları (Doğru, 2017), cesaret (Can ve Kaçay, 2016), diğerleriyle olumlu ilişkiler ve yaşam amacı (Bilgin, 2017) ile pozitif ilişki içinde olduğu görülürken; boyun eğici davranışlar (Cengiz, Arslan ve Şahin, 2015), mükemmeliyetçi benlik sunumu (Ceylan, 2017), olumsuz değerlendirilme korkusu (Tosun, 2013), şiddet eğilimi (Patır Erkek, 2016), sosyal fobi (Sağat, 2016), sosyal anksiyete düzeyi (Parçal, 2018), zorbalık (Umutlu, 2010), olumsuz beden imajı (Oktan ve Şahin, 2010), sınav kaygısı (Başoğlu, 2007), stres ve sağlik şikayetleri (Hidingh, Luepker, Baigi ve Lidell, 2006) ile negatif ilişki içinde olduğu görülmektedir. Bireyin yaşamını olumlu ya da olumsuz olarak değiştirebilen özgüven düzeyini nelerin etkilediğinin bilinmesi bu noktada önem arz etmektedir. Bireyin özgüven düzeyini etkileyen birçok farklı faktör bulunmaktadır. Bu faktörler arasında birinci sırada olan faktör anne ve baba tutumlarıdır. İkinci faktörler ise yaşanılan çevre ve toplumdur. Bireyin yaşadığı hayal kırıklıkları, baskıcı yetişme tarzı, travmalar, yanlış yönlendirme, akademik başarı gibi durumlarda özgüveni zedelemektedir (Sarı, 2016).

Türkiye'de özgüven ile ilgili yapılan lisansüstü tezler eğitim alanında yoğunlaşsa da spor, işletme, sağlık gibi birçok farklı alanda bu kavram ile ilgili çalışmaların yapıldığı görülmektedir. Bireyin yaşamının her anını etkileyen özgüven kavramı ile çok sayıda çalışma yapılmış olması araştırmacılar için değerli olmakla birlikte bu çalışmaların hangi yöntem 
ve analiz teknikleriyle, hangi örneklem gruplarına ve hangi alanlarda yoğunlaşarak yapıldığının tespit edilmesi de önemli görülmektedir.

Yapılan literatür incelemesinde ülkemizde özgüven ile ilgili yapılmış lisansüstü tezlerde çalışılan konuların yönelimlerini belirleyen kapsamlı bir analiz çalışmasının bulunmadığı görülmektedir. Bu çalışmanın amacı ülkemizde özgüven ile ilgili yapılan hem yüksek lisans hem de doktora düzeyindeki lisansüstü çalışmaların incelenmesidir.

\section{Yöntem}

\section{Araştırmanın Modeli}

Bu araştırma betimsel bir çalışma olup bu kapsamda doküman incelemesi yapılarak Türkiye'de özgüven ile ilgili yapılmış lisansüstü tezler incelenmiştir.

\section{Örneklem}

Araştırmanın örneklemi Yüksek Öğretim Kurulu Ulusal Tez Merkezi'ne 1995-2018 yılları arasında kayıtlı özgüven ile ilgili yapılmış 76 yüksek lisans ve 15 doktora tezi olmak üzere toplam 91 tezden oluşmaktadır.

İncelenen lisansüstü tezlerin yapıldıkları üniversitelere göre dağılımı şu şekildedir: Marmara Üniversitesi (8), Dokuz Eylül Üniversitesi (6), Orta Doğu Teknik Üniversitesi (6), Gazi Üniversitesi (4), Atatürk Üniversitesi (3), Hacettepe Üniversitesi (3), Karadeniz Teknik Üniversitesi (3), Maltepe Üniversitesi (3), Nişantaşı Üniversitesi (3), Sakarya Üniversitesi (3), Selçuk Üniversitesi (3), Adnan Menderes Üniversitesi (2), Ankara Üniversitesi (2), Beykent Üniversitesi (2), Boğaziçi Üniversitesi (2), Fırat Üniversitesi (2), Gelişim Üniversitesi (2), İhsan Doğramacı Bilkent Üniversitesi (2), On dokuz Mayıs Üniversitesi (2), Süleyman Demirel Üniversitesi (2), Van Yüzüncü Yll Üniversitesi (2), Yeditepe Üniversitesi (2), Ankara Yıldırım Beyazıt Üniversitesi (1), Avrasya Üniversitesi (1), Bahçeşehir Üniversitesi (1), Bartın Üniversitesi (1), Çağ Üniversitesi (1), Düzce Üniversitesi (1), Ege Üniversitesi (1), GATA (1), Gebze İleri Teknoloji Enstitüsü (1), Haliç Üniversitesi (1), İnönü Üniversitesi (1), İstanbul Arel Üniversitesi (1), İstanbul Aydın Üniversitesi (1), İstanbul Bilim Üniversi- 
tesi (1), İstanbul Üniversitesi (1), Kahramanmaraş Sütçü İmam Üniversitesi (1), Manisa Celal Bayar Üniversitesi (1), Mersin Üniversitesi (1), Muğla Sıtkı Koçman Üniversitesi (1), Necmettin Erbakan Üniversitesi (1), Siirt Üniversitesi (1), Türk Hava Kurumu Üniversitesi (1) , Uludağ Üniversitesi (1), Yalova Üniversitesi (1).

Özgüven ile ilgili yapılan lisansüstü tezlerin üniversitelere göre dağ1lımı incelendiğinde 91 yayının 46 farklı üniversitede yapıldığı görülmektedir. En fazla yayın yapılan üniversitenin 8 yayın ile Marmara Üniversitesi olduğu görülürken onu 6'şar yayın ile Dokuz Eylül Üniversitesi ve Orta Doğu Teknik Üniversitesi izlemektedir.

\section{Verilerin Analizi}

Araştırmada veri toplama yöntemi olarak doküman analizi kullanılmıştır. Doküman analizi mevcut kayıt ya da belgelerin veri kaynağı olarak sistemli bir şekilde incelenmesidir (Karadağ, 2009). Bu doğrultuda araştırma örneklemini oluşturan lisansüstü tezler yapıldığı yıl, yapıldığı enstitü/bilim dalı, örneklem grupları, kullanılan desen/yöntem, model, veri analiz teknikleri, birlikte çalışıldığı konu alanlarına göre ayrılarak çözümlenmiş, araştırma sonuçları hakkında bilgi verilmiş ve sonuçlar doğrultusunda önerilerde bulunulmuştur.

\section{Bulgular}

Bu araştırmada 1995-2018 yılları arasında özgüven ile ilgili yapılmış 76 yüksek lisans ve 15 doktora olmak üzere toplam 91 lisansüstü tez örnekleme dâhil edilmiş ve bu tezler üzerinden doküman incelemesi yapılmıştır. Örnekleme dâhil edilen lisansüstü tezlerin yapıldıkları yıllara göre dağılımı Tablo 1'de gösterilmiştir.

Tablo 1 incelendiğinde; son yıllarda özgüven ile ilgili yapılan lisansüstü çalışmalarda artış olduğu ve bu artışın özellikle yüksek lisans tezlerinde 2012 yılı ve sonrasında olduğu görülmektedir. Lisansüstü yayınların en çok yoğunlaştığı iki yılın 14'er yayınla 2016 ve 2018 yılları olduğu görülmektedir. Örnekleme dâhil edilen tezlerin bağlı bulundukları enstitü ve bilim/anabilim dalları Tablo 2'de gösterilmiştir. 
Türkiye'de Özgüven ile İlgili Yapılan Lisansüstü Tezlerin İncelenmesi

Tablo 1. Örnekleme dâhil edilen yüksek lisans ve doktora tezlerinin yıllara göre

\begin{tabular}{lll} 
dă̆ılımı & Yüksek Lisans & Doktora \\
\hline Yıllar & - & 1 \\
\hline 1995 & 1 & - \\
1998 & 2 & - \\
2001 & 1 & 1 \\
2002 & 3 & - \\
2004 & 1 & 1 \\
2005 & 3 & 1 \\
2006 & 4 & - \\
2007 & - & 1 \\
2008 & 2 & - \\
2009 & 3 & 2 \\
2010 & 2 & - \\
2011 & 6 & 1 \\
2012 & 5 & - \\
2013 & 6 & 1 \\
2014 & 6 & 1 \\
2015 & 12 & 2 \\
2016 & 6 & 2 \\
2017 & 13 & 1 \\
2018 & $\mathbf{7 6}$ & $\mathbf{1 5}$ \\
\hline TOPLAM & &
\end{tabular}

Tablo 2. Örnekleme dâhil edilen lisansüstü tezlerin enstitüleri

\begin{tabular}{|c|c|c|c|}
\hline Enstitü & Bilim Dalı/Anabilim Dalı & $\mathrm{f}$ & $\%$ \\
\hline \multirow{9}{*}{$\begin{array}{c}\text { Sosyal } \\
\text { Bilimler }\end{array}$} & Psikoloji & 15 & 16 \\
\hline & Eğitim Bilimleri & 10 & 11 \\
\hline & İktisadi ve İdari Bilimler(Yönetim bilimleri-işletme-kamu yönetimi-iktisat-çeko) & 8 & 9 \\
\hline & Turizm işletmeciliği & 1 & 1 \\
\hline & Sosyal hizmetler & 1 & 1 \\
\hline & Yabancı diller & 3 & 3 \\
\hline & Felsefe ve din bilimleri & 3 & 3 \\
\hline & Grafik tasarım & 1 & 1 \\
\hline & Beden eğitimi ve spor & 1 & 1 \\
\hline \multirow{8}{*}{$\begin{array}{l}\text { Eğitim } \\
\text { Bilimleri }\end{array}$} & Güzel sanatlar & 6 & 7 \\
\hline & Eğitimde psikolojik hizmetler-pdr & 5 & 5 \\
\hline & Beden eğitimi ve spor & 5 & 5 \\
\hline & Eğitim bilimleri-(eğitim programları ve öğretimi, ölçme ve değerlendirme) & 6 & 7 \\
\hline & Aile eğitimi ve danışmanlığı- çocuk gelişimi & 2 & 2 \\
\hline & Yabancı diller & 1 & 1 \\
\hline & Matematik ve fen bilimleri & 2 & 2 \\
\hline & İlköğretim & 4 & 4 \\
\hline Sağlık & Beden eğitimi ve spor & 9 & 10 \\
\hline Bilimleri & Sağlık (çocuk sağlığı ve hemşirelik-cerrahi hastalıklar-sağlık yönetimi-ebelik) & 6 & 7 \\
\hline $\begin{array}{c}\text { Fen } \\
\text { Bilimleri }\end{array}$ & Bilgisayar ve Öğretim Teknolojileri & 2 & 2 \\
\hline
\end{tabular}


Tablo 2' de özgüven ile ilgili lisansüstü tezlerin yapıldıkları enstitüler ve bilim/anabilim dalları incelendiğinde en çok lisansüstü yayın Sosyal Bilimleri Enstitüsünde (43) yapılmıştır. Onu 31 yayın ile Eğitim Bilimleri Enstitüsü, 15 yayın ile Sağlık Bilimleri Enstitüsü ve 2 yayın ile Fen Bilimleri Enstitüsü takip etmektedir. Özgüven ile ilgili lisansüstü tezlerin yapıldıkları bilim/anabilim dalları incelendiğinde tezlerin eğitim bilimleri alanında yoğunlaştığ1 görülmektedir. Bu alanda toplam 21 lisansüstü yayın yapıldığı tespit edilmiştir. Eğitim Bilimleri alanını 15'er yayınla Psikoloji ve Beden Eğitimi ve Spor bilim dallarının takip ettiği görülmektedir. Örnekleme dâhil edilen lisansüstü tezlerin uygulandığ 1 örneklem gruplarına göre dağılımı Tablo 3'de gösterilmiştir.

Tablo 3. Örnekleme dâhil edilen lisansüstü tezlerin örneklem grupları

\begin{tabular}{lll}
\hline Örneklem Grubu & f & \% \\
\hline Çocuk & 3 & 3 \\
İkokul & 8 & 9 \\
Ortaokul & 16 & 18 \\
Lise/Ergen & 17 & 19 \\
Üniversite/Genç Yetişkin & 17 & 19 \\
Yetişkin & 25 & 27 \\
Karma & 3 & 3 \\
Eser İncelemesi (örneklem yok) & 2 & 2 \\
\hline
\end{tabular}

Tablo 3 incelendiğinde özgüven ile ilgili yapılan lisansüstü tezlerin en yoğun olarak yetişkin örneklem üzerinde çalışıldığ görülmektedir. 25 yayının yapıldığı bu grubu 17'şer yayınla lise/ergen ve üniversite öğrencisi olan genç yetişkin grubu izlemektedir. Ortaokul grubu üzerinde 16 yayının yapıldığı görülürken onu sırasıyla 8 yayınla ilkokul, 3'er yayınla çocuk grubu ve karma grup takip etmektedir. Yayınlar incelendiğinde herhangi bir örneklem grubu olmayan eser incelemesi yapılarak analiz edilen 2 lisansüstü yayın olduğu görülmektedir. Örnekleme dâhil edilen lisansüstü yayınların yapıldıkları desen türüne ilişkin frekans ve yüzde değerleri Tablo 4'te gösterilmiştir.

Tablo 4. Örnekleme dâhil edilen lisansüstü tezlerin deseni

\begin{tabular}{lll}
\hline Kullanılan Desen & f & $\%$ \\
\hline Nicel & 76 & 83 \\
Nitel & 6 & 7 \\
Karma & 9 & 10 \\
\hline
\end{tabular}


Tablo 4 incelendiğinde özgüven ile ilgili yapılan lisansüstü tezlerin 76'sının nicel, 9'unun karma ve 6'sının nitel desenle yapıldığg görülmektedir. Nicel desenle yapılan çalışmalarda yoğunluk olduğu ve lisansüstü çalışma yapan araştırmacıların en çok bu deseni kullandığı söylenebilir. Örnekleme dâhil edilen lisansüstü tezlerin kullandıkları model/yönteme göre frekansları Tablo 5'te gösterilmiştir. Bir yayında birden fazla model/yöntem kullanılabileceğinden yüzdelik değerleri hesaplanmamıştır.

Tablo 5. Örnekleme dâhil edilen lisansüstü tezlerde kullanılan model/yöntem

\begin{tabular}{ll}
\hline Kullanılan Model/Yöntem & f \\
\hline Deneysel & 23 \\
Doküman-İçerik Analizi/Fenomenoloji/Görüşme/Gözlem & 15 \\
Tarama & 61 \\
\hline
\end{tabular}

Tablo 5 incelendiğinde araştırmacılar tarafından en çok tercih edilen yöntemin tarama yöntemi olduğu görülmektedir. Araştırmacıların lisansüstü tezlerinde bu yöntemi $61 \mathrm{kez}$ tercih ettikleri tespit edilmiştir. Lisansüstü tezlerde tercih edilen bir diğer yöntem ise deneysel yöntemlerdir. 23 yayının yapıldığı deneysel yöntemi 15 yayınla nitel araştırmalarda kullanılan doküman incelemesi, fenomenoloji, görüşme ve gözlem yöntemleri takip etmektedir. Örnekleme dâhil edilen lisansüstü tezlerde kullanılan veri analiz tekniklerinin dağ 1 lımı Tablo $6^{\prime}$ da gösterilmiştir. Bir yayında birden fazla veri analiz tekniği kullanılabileceğinden yüzde değerleri hesaplanmamıştır.

Tablo 6. Örnekleme dâhil edilen lisansüstü tezlerin veri analiz teknikleri

\begin{tabular}{ll}
\hline Veri Analiz Tekniği & $\mathbf{f}$ \\
\hline ANOVA & 38 \\
t-testi & 19 \\
Regresyon & 10 \\
ANCOVA & 1 \\
MANOVA & 2 \\
Betimsel & 8 \\
Korelasyon & 32 \\
Faktör Analizi & 2 \\
Non-Parametrik Testler & 17 \\
İçerik Analizi & 7 \\
\hline
\end{tabular}


Tablo 6 incelendiğinde özgüven ile ilgili yapılan lisansüstü tezlerde en çok kullanılan veri analiz tekniklerinin sırasıyla ANOVA (38), korelasyon (32), t-testi (19) ve Non-Parametrik testler (17) olduğu görülmektedir. Yayınlarda en az tercih edilen veri analiz teknikleri ise ANCOVA, MANOVA ve faktör analizidir. Örnekleme dâhil edilen lisansüstü tezlerde özgüven ile birlikte çalışılan konu alanlarına ilişkin frekans değerleri Tablo 7'de gösterilmiştir. Bir yayında birden fazla konu alanı olabileceğinden yüzdelik değerleri hesaplanmamıştır.

Tablo 7. Örnekleme dâhil edilen lisansüstü tezlerin birlikte çalışıldığı konu alanları

\begin{tabular}{ll}
\hline Konu Alanı & $\mathbf{f}$ \\
\hline Eğitim-Öğretim (Akademik başarı, derse karşı tutum, çoklu zeka, pedagojik) & 16 \\
\hline Spor/Beden Eğitimi & 15 \\
\hline Aile (Anne-baba tutumu, aile işlevleri, aile içi şiddet, aile uyumu) & 13 \\
\hline Sanat (Dans, müzik, drama, görsel sanatlar) & 14 \\
\hline Teknoloji & 7 \\
\hline Pozitif Psikoloji (Yaşam amacı, mutluluk, psikolojik dayanıklılık, affedicilik) & 7 \\
\hline Psikolojik Belirtiler/Davranış Bozuklukları (Kaygı, depresyon, sosyal fobi) & 9 \\
\hline Davranış Problemleri (zorbalık, öfke kontrol, şiddet eğilimi, mükemmeliyetçilik) & 9 \\
\hline İş Yaşamı (Yönetici, çalışan, kurumsal) & 6 \\
\hline Deneysel uygulamalar, eğitimler (Psikolojik danışma kuramları) & 4 \\
\hline Dil (Yabancı dil, dil edinimi) & 4 \\
\hline Maneviyat/Din & 3 \\
\hline Beden Algısı & 2 \\
\hline Diğer & 2 \\
\hline
\end{tabular}

Örnekleme dâhil edilen konu alanları belirlenirken kapsamlı bir alan yazın incelemesi yapılmıştır. Ayrıca belirlenen konu alanları ile ilgili psikolojik danışmanlık ve rehberlik alanında uzman öğretim üyelerinin görüşleri alınmıştır. Özgüven ile ilgili yapılan lisansüstü tezlerin birlikte çalışıldığı konu alanları incelendiğinde; Eğitim-öğretim ile ilgili konuların 16, spor/beden eğitimi ile ilgili konuların 15, sanat ile ilgili konuların 14, aile ile ilgili konuların 13, psikolojik belirtiler/davranış bozuklukları ile ilgili konuların 9, davranış problemleri ile ilgili konuların 9, teknoloji ile ilgili konuların 7, pozitif psikoloji ile ilgili konuların 7, iş yaşamı ile ilgili konuların 6, dil edinimi ile ilgili konuların 4, maneviyat/din ile ilgili konuların 3 ve beden algısı ile ilgili konuların 2 defa çalışıldığı tespit edilmiştir. 2 yayın ise belirlenen konu alanlarının herhangi birisinin içerisine yerleştirilememiştir. Bu yayınlardan birisi özgüveni uyruklar arası 
karşılaştırırken (Çevik, 2015) diğer yayında özgüven ile bireyselciliktoplulukçuluk (Anamur, 1998) arasındaki ilişkiye bakıldığı görülmektedir.

Elde edilen bu bulgular doğrultusunda özgüven ile ilgili yapılmış lisansüstü yayınların çoğunlukla eğitim-öğretim, spor/beden eğitimi, sanat ve aile konu alanlarında yoğunlaştığ 1 söylenebilir. Bu konu alanlarını ise davranış bozukları ve davranış problemleri ile ilgili konuların izlediği görülmektedir. Eğitim- öğretim ile ilgili yapılan yayınlar geniş bir yelpazeye yayılmakla birlikte en çok akademik başarı, derse karşı tutum ve pedagojik konuların çalışıldığ 1 görülmektedir. Spor ve beden eğitimi alanında çok farklı spor dalları/branşları ile çalışmaların yapıldığı görülürken, sanat alanında müzik ve yaratıcı drama konularında yoğunluk olduğu tespit edilmiştir. Aile alanında yapılan çalışmalar incelendiğinde çalışmaların çoğunlukla anne baba tutumu, aile işlevleri, aile uyumu, aile içi şiddet konularında yapıldığı söylenebilir. Davranış bozukluğu ve davranış problemleri ile ilgili de birçok yayının yapıldığı söylenebilir. Bu yayınların daha çok anksiyete/kaygı, sosyal fobi, öfke kontrol sorunu, şiddet eğilimi, mükemmeliyetçilik gibi konu alanlarında yapıldığı söylenebilir.

\section{Tartışma ve Sonuç}

Bu araştırmada Türkiye'de 1995-2018 yılları arasında özgüven ile ilgili yapılmış lisansüstü tezlerin incelenmesi amaçlanmıştır. Bu amaç doğrultusunda 76 yüksek lisans ve 15 doktora tezi olmak üzere toplam 91 tez yapıldığı yıl, enstitü/bilim dalı, örneklem grubu, deseni, model ve yöntemi, veri analiz tekniği ve konu alanı açısından incelenmiştir. Özellikle son yıllarda Türkiye'de çeşitli konularda yapılan lisansüstü tezlerin incelenmesine yönelik çok sayıda araştırma yapıldığı görülmektedir (Ataseven ve Oğuz, 2015; Beyazıt, 2015; Yaşar ve Papatğa, 2015; Koç, 2016; Alpaydın ve Erol, 2017; Püsküllüoğlu ve Hoşgörür, 2017; Aydın, Selvitopu ve Metin; 2018; Tosun Sümer ve Güven, 2018; Güngören, Erdoğan ve Ayas, 2018; Kapkın, Çalışkan ve Sağlam, 2018; Değirmenci Gündoğmuş, 2018). Literatür incelendiğinde Türkiye'de özgüven kavramı ile ilgili yapılan lisansüstü çalışmaların incelendiği bir çalışmaya rastlanmamıştır. Bu çalışma insan hayatının her anını pozitif ya da negatif olarak etki- 
leyebilen özgüven kavramı ile ilgili çalışmaların içeriğini ortaya koyması açısından önemli olarak görülmektedir.

Araştırma sonucunda elde edilen bulgulara göre özgüven ile ilgili yapılmış lisansüstü tezlerin sayısında özellikle de yüksek lisans grubunda son yıllarda ciddi bir artış olduğu görülmüştür. Kaytaz ve Durualp (2014)'ın Türkiye'de okul öncesi dönemde oyun ile ilgili yapılan lisansüstü tezleri inceledikleri çalışmalarında 1986-2013 yılları baz alınmış ve özellikle de 2004-2013 yılları arasında yüksek lisans tezlerinin sayısında bir artış olduğu belirtilmiştir. Benzer bulguya ulaşılan bir diğer araştırmada 1990-2010 yılları arasında Türkiye' de okul öncesinde drama alanında yapılan lisansüstü tezler incelenmiş ve 2004-2009 yılları arasında yüksek lisans tezlerinde bir artış olduğu tespit edilmiştir (Yaşar, 2011). Bu sonuçlar bu araştırmanın bulgusu ile paralellik göstermektedir. Son yıllarda ülkemizde artan üniversite sayısına istinaden yeni açılan enstitüler ve lisansüstü programların bu sonucu doğurduğu düşünülebilir. Diğer yandan günümüzde ailelerin bilinçlenmesi sonucu özgüven kavramının öneminin artık bilinmesi ve çocukların özgüvenli bir birey olarak yetişmesinin ona getireceği faydaların toplumun her kesimi tarafından fark edilmesi sonucu giderek önemi artan özgüven kavramı ile ilgili yapılan çalışmalara araştırmacıların ağırlık verdiği söylenebilir. Türkiye'de özgüven ile ilgili yapılmış lisansüstü tezler yapıldığ1 enstitü ve bilim/anabilim dalına göre incelendiğinde en çok çalışmanın sosyal bilimler ve eğitim bilimleri enstitüsünde yapıldığı bulunmuştur. Yayınların yapıldıkları bilim/anabilim dalları incelendiğinde çalışmaların eğitim bilimleri alanında, spor alanında ve psikoloji alanında yoğunlaştığı görülmüştür. Bu sonucun beklenen bir bulgu olduğu söylenebilir. Literatürde özgüveni etkileyen faktörlerin genellikle aile, çevre, okul başarısı, baskı ve disiplin yöntemleri, fiziksel görünüm (Kasatura, 1998; Kocaarslan, 2009; Göknar, 2010; Altan, 2001; Sar1; 2016) gibi kavramlar olduğunun belirtilmesi ve bu kavramların ağırlıklı olarak sosyal bilimler, eğitim bilimleri ve psikoloji alanının konuları olduğu düşünülürse bu araştırmanın bulguları ile literatür bilgisinin benzerlik gösterdiği düşünülebilir.

$\mathrm{Bu}$ çalı̧̧manın bir diğer bulgusuna göre özgüven ile ilgili yapılan lisansüstü yayınlarda en çok çalışılan örneklem grubu yetişkin gruptur. Yetişkin grubu sırasıyla üniversite öğrencileri, lise (ergen) grubu ve ortaokul grubu izlemektedir. Çocuk grubu ise en az çalışılan örneklem grup- 
larından birisidir. Literatür incelendiğinde özgüvenin doğuştan getirilen kalıtsal bir özellik olmadığı ve birey yaşadıkça çeşitli faktörler aracılığı ile şekillendiği söylenmektedir (Hambly, 2003; Göknar, 2010). Diğer çalışmalarda benzer olarak özgüvenin statik durağan olmadığı temellerinin bebeklik döneminde atıldığı fakat yaşam boyu gelişmeye devam eden bir özellik olduğu belirtilmektedir (Özbey, 2004; Lauster, 2010). Bu bilgiler ışığında özgüvenin yaşamın her döneminde çalışılabilecek bir konu olduğu görülmektedir. Bu çalışmada özgüven ile ilgili yapılan lisansüstü tezlerde en çok yetişkin örneklemi kullanıldığ bulunmuştur. $\mathrm{Bu}$ araştırmanın bulgularına benzer sonuca Seçer ve diğerleri (2014)'nin çalışmasında ulaşıldığ 1 görülmüştür. Çalışmada en fazla kullanılan örneklemin üniversite öğrencileri olduğu ve bunun nedeninin yetişkin grubun kolay ulaşılan grup olduğu ve diğer ilkokul, ortaokul, lise grubunda izin alma süreçlerinin zor ve uzun olması gösterilmektedir (Seçer ve diğerleri, 2014; Arık ve Türkmen, 2009). Bu çalışma bulgularına göre üstünde durulması gereken bir diğer konu çocukluk döneminde özgüven ile ilgili yapılan tez sayısının çok düşük olmasıdır. Özgüvenin temellerinin bebeklik dönemi ile atılmaya başladığı düşünüldügünde ve anne baba tutumlarının özgüven üzerindeki etkisiyle birlikte çocukluk dönemi ve devamında ergenlik dönemine kadar özgüvenin oluşumu ve gelişiminin kararlı bir şekilde gerçekleştiği düşünülebilir. Her ne kadar özgüven yaşam boyu gelişmeye devam eden bir olgu olsa dahi ergenlik döneminden sonra bireylerin kişilik özelliklerinin daha kalıcı bir şekilde yerleştiği ve bireyde oluşan özellikleri değiştirmenin zorlaşabileceği düşünüldügünde özgüven ile ilgili yapılan çalışmalara bebeklik döneminden itibaren başlamanın önemli olduğu söylenebilir. Bu çalışmanın bulgularına göre dikkat çeken bir diğer nokta ise yaşlı örneklem grubu ile özgüven konusunda yapılmış herhangi bir lisansüstü yayına rastlanmamış olmasıdır.

Araştırmanın bir diğer bulgusuna göre özgüven ile ilgili yapılan lisansüstü tezlerde araştırmacıların en çok tercih ettikleri desen büyük bir farkla nicel araştırma deseni olmuştur. Nitel desenle yapilan araştırmaların oldukça kısıtlı olduğu saptanırken karma deseninde çok az sayıda kullanıldığ1 tespit edilmiştir. Arık ve Türkmen (2009) bu araştırmanın bulgularına benzer olarak eğitim bilimleri alanında yayınlanan dergilerdeki makaleleri inceledikleri çalışmaları sonucunda en çok kullanılan 
desenin nicel desen olduğunu belirtmiştir. Yine benzer şekilde 2005-2006 yılları arasında eğitim bilimleri alanında yapılan makalelerin incelendiği başka bir çalışmada en çok tercih edilen desenin nicel desen olduğu görülmektedir (Erdem, 2011). Seçer ve diğerleri (2014)'de bu çalışmanın bulgusuna paralel olarak rehberlik ve psikolojik danışma alanındaki araştırma eğilimlerini inceledikleri çalışmaları sonucu araştırmalarda nicel analiz yöntemlerinin çok yoğun olarak kullanıldığını ve nitel araştırma yöntemlerine çok az yer verildiğini belirtmişlerdir. Benzer şekilde Kurtoğlu ve Seferoğlu (2013) yaptıkları çalışma sonucunda inceledikleri makalelerde en çok kullanılan desenin nicel araştırma desenleri olduğunu söylemektedir. Bu çalışmada elde edilen bir diğer bulguya göre nicel araştırma deseni kullanılan çoğu araştırmada yöntem olarak tarama yöntemi tercih edildiği ve deneysel yöntemlerin daha az kullanıldığı görülmüştür. Araştırmalarda nitel analiz deseni için en çok tercih edilen yöntemin ise dokuman/içerik analizi yöntemi olduğu bulunmuştur. Bu durumun sonucu olarak araştırmaların kullanılan yöntem açısından sınırl1lıklar barındırdığı ve nicel araştırma yöntemlerinin çok fazla kullanılması sebebiyle var olan durumu ortaya koymanın ötesine geçilemediği düşünülebilir.

Bu çalışmada ayrıca özgüven ile ilgili yapılan lisansüstü tezlerde kullanılan veri analiz teknikleri de incelenmiştir. Tezlerde en çok sırasıyla ANOVA, korelasyon ve t-testi tekniklerinin kullanıldığı görülmüştür. Literatür incelendiğinde bu araştırmanın sonuçlarına benzer bulgulara ulaşıldığı görülmektedir. Erdem (2011) yaptığı çalışmasında eğitim bilimi alanındaki araştırmalarda en çok t-testi, ANOVA ve betimsel istatistiklerin kullanıldığını belirlemiştir. Seçer ve diğerleri (2014)'de araştırmalarda sirasıyla en fazla ortalama/standart sapma değerleri, ANOVA, korelasyon ve t-testi kullanıldığını söylemişlerdir. Bu çalışmanın bulgularına göre nitel analiz tekniği olarak en çok kullanılan analiz tekniği ise içerik analizidir. Nicel analiz tekniklerinin bu kadar fazla kullanılmasına rağmen ANCOVA ve MANOVA gibi tekniklerin çok az kullanılmasının nedeninin araştırmacıların kendi bildikleri ve hakim oldukları analiz tekniklerini uygulamalarından kaynaklı olduğu düşünülebilir.

Son olarak bu araştırmada özgüven ile ilgili yapılan lisansüstü tezlerin birlikte çalışıldığı konu alanları incelenmiştir. Bulgulara göre özgüvenin sırasıyla en çok eğitim-öğretim (akademik başarı, derse karşı tu- 
tum, çoklu zeka, pedagojik), spor/beden eğitimi, aile (anne-baba tutumu, aile işlevleri, aile içi şiddet, aile uyumu), sanat (dans, müzik, drama, görsel sanatlar), psikolojik belirtiler/davranış bozuklukları (kaygı, depresyon, sosyal fobi), davranış problemleri (zorbalık, öfke kontrol, şiddet eğilimi, mükemmeliyetçilik), teknoloji ve pozitif psikoloji (yaşam amacı, mutluluk, psikolojik dayanıklılık, affedicilik) konularında çalışıldığı görülmektedir. Özgüven kavramının özellikleri ve bu kavramla etkileşimli olabilecek konular düşünüldügünde bu bulgunun beklenildiği gibi olduğu söylenebilir.

\section{Öneriler}

$\mathrm{Bu}$ araştırmada ulaşılan bulgular ışığında nicel araştırmaların yanında nitel araştırmalara da yer verilen kapsamlı çalışmaların yapılabileceği, nicel araştırma desenlerinde de tarama yönteminden ziyade deneysel yöntemlere daha fazla ağırlık verilebileceği söylenebilir. Bu araştırma kapsamındaki çalışmaların birçoğunda kolay ulaşılabilen yetişkin, üniversite öğrencileri ve ergen grupların kullanıldığı görülmüştür. Bu nedenle yalnızca bu gruplara değil tüm örneklem gruplarına ulaşılabilecek geçerliği ve güvenirliği daha yüksek çalışmaların yapılabileceği önerilebilir. Özellikle özgüvenin yaşlı grubu ile birlikte ele alındığı herhangi bir çalışmaya rastlanmamış olmasından dolayı yaşlı grubunda özgüven ile ilgili çalışmalar yapılabilir. Araştırmalarda veri analiz teknikleri belirlenirken daha çok araştırmacıların kendi hakim oldukları analiz tekniklerini kullandığı görülmüştür. Bundan sonraki çalışmalarda araştırma yöntemine ve problemine en uygun analiz tekniği seçilebilir. Çalışmalarda ileri analiz tekniklerine daha fazla yer verilebilir. Özgüven ile ilgili yurtdışında ki bilimsel araştırma eğilimlerinin karşılaştırılmasına yönelik çalışmalar yapılabilir. 


\title{
EXTENDED ABSTRACT
}

\section{Investigation of the Postgraduate Theses Performed on Self-Confidence in Turkey}

\author{
Okan Bilgin \\ Zonguldak Bülent Ecevit University
}

Self-confidence is defined as self-recognition, loving oneself, believing that they can be aware of their abilities and emotions (Altıntaş, 2015) and continues to develop throughout life starting from infancy (Özbey, 2004; Lauster, 2010). According to Bandura (1997), self-confidence is the judgment of feeling self-worth. Hambly (2003) defines self-confidence as an individual's belief in his / her own abilities and courage. Self-confidence, one of the most basic characteristics of human personality, is not hereditary and it is shaped as human beings live. Self-confidence, which is a subjective phenomenon of self-evaluation, can be high, low, or moderate. The self-confidence level of an individual can affect his / her emotions and behaviors in different directions (Soner, 1995). People with low selfconfidence often put themselves in the background. Valuelessness belief of these people are so high and they don't have the courage to take risks (Başoğlu, 2007). On the other hand, moderate self-confident people who have a mixture of positive and negative experiences cannot be autonomous even if they rely on their own experiences from time to time (Humphreys, 2002). Individuals with a high level of self-confidence accept life and others as they are by living life in a balance (Altıntaş, 2015). At this point, it is important to know what affects the level of selfconfidence that can change an individual's life positively or negatively. There are many different factors that affect the level of self-confidence. The first factor among these is the attitudes of parents and the second factor is the environment and society. Self-frustration, repressive upbringing, traumas, misguidance, and academic success may damage self-confidence (Sar1, 2016).

It is valuable for the researchers to have conducted many studies with the concept of self-confidence affecting every moment of an individual's 
life, it is crucial to determine which methods and analysis techniques in these studies are conducted by focusing on which sample groups and in which areas as well.

The aim of this study was to investigate postgraduate studies on selfconfidence in Turkey.

This research was a descriptive study. The sample of the study consisted of a total of 91 theses, 76 master and 15 doctoral theses about selfconfidence registered to the Higher Education Council National Thesis Center between 1995-2018. In the research, document analysis was used in data collection process. Document analysis is a systematic review of existing records or documents as data sources (Karadağ, 2009). In this context, the postgraduate theses that make up the research sample were investigated according to the year of study, the institute / science branch, sample groups, method, model, data analysis techniques used and the subject fields.

According to the findings of the research, there was a significant increase in the number of postgraduate theses about self-confidence especially in the master group in recent years. When the institutes where the postgraduate theses about self-confidence were examined, the highest number of graduate publications was prepared in the Institute of Social Sciences. The thesis that prepared in the Institute of Social Sciences were followed by the thesis that prepared in Institute of Educational Sciences, the Institute of Health Sciences and the Institute of Science respectively. When the science departments of the publications were examined, it was seen that the studies were focused on educational sciences, sports and psychology.

According to another finding of this study, adult group was the most studied sample in graduate publications on self-confidence. The adult group was followed by university students, high school (adolescent) group and secondary school group respectively. The children group was one of the least studied sample groups. In the postgraduate theses about self-confidence, the most preferred design of the researchers was a quantitative research design with a big difference. While the qualitative researches were found to be quite limited, it was found that there was very low use in mixed design.In this study, data analysis techniques used in graduate theses about self-confidence were also examined. ANOVA, 
correlation and t-test techniques were used the most. Finally, when the concepts studied with self-confidence were investigateed, it was found that self-confidence was mainly focused on education, family, sports and arts.

In the light of the findings obtained in this study, it can be suggested that comprehensive studies including qualitative studies can be carried out besides quantitative studies. Besides it can be said that in quantitative research designs, more emphasis can be placed on experimental methods rather than survey methods. It can be recommended that more valid and reliable studies can be conducted to reach all sample groups, not just the adult group.Advanced analysis techniques may be included more in the studies. Studies can be conducted to compare the scientific research trends abroad about self-confidence.

\section{Kaynakça / References}

Akkuş, Z. (2015). Ergenlerde psikolojik dayanıklılığın özgüven ve anne baba tutumları ile ilişkisi. Yayınlanmamış yüksek lisans tezi. Dokuz Eylül Üniversitesi Eğitim Bilimleri Enstitüsü, İzmir.

Alpaydın, Y., ve Erol, İ. (2017). Türkiye'de eğitim ekonomisi alanında yapilan lisansüstü tezlerin incelenmesi. Marmara Üniversitesi Atatürk Ĕ̆itim Fakültesi Eğitim Bilimleri Dergisi, 45(45), 23-41.

Altan, A. (2001). Body image dissatisfaction, self-esteem and anxiety in plastic surgery patients. Yayınlanmamış Yüksek Lisans Tezi, Boğaziçi Üniversitesi Sosyal Bilimler Enstitüsü, İstanbul.

Altıntaş, E. (2015). Kuramdan uygulamaya özgüven. Nobel Akademik Yayınc1lik: Ankara.

Anamur, N. Z. (1998). Individualism-collectivism, self-concept and sources of selfesteem. Yayınlanmamış yüksek lisans tezi. Boğaziçi Üniversitesi, Sosyal Bilimler Enstitüsü. İstanbul.

Arık, R. S. ve Türkmen, M. (2009). Eğitim bilimleri alanında yayımlanan bilimsel dergilerde yer alan makalelerin incelenmesi. I. Uluslararasi Türkiye Eğitim Araştırmalarn Kongresi'nde sunulan sözel bildiri, 1-3 Mayıs, 2009, Çanakkale.

Arslan, E. (2008), Bă̆lanma stilleri açısından ergenlerde erikson'un psikososyal gelişim dönemleri ve ego kimlik süreçlerinin incelenmesi, Yayınlanmamış Doktora Tezi, Selçuk Üniversitesi Sosyal Bilimleri Enstitüsü, Konya. 
Aslan, Y. (2016). Lise son sinı öğrencilerinin affedicilik özelliği ile özgüven düzeyleri arasındaki iliş̧i. Yayınlanmamış yüksek lisans tezi. Nişantaşı Üniversitesi, Sosyal Bilimler Enstitüsü, İstanbul.

Ataseven, A. G. N., ve Oğuz, A. (2015). Türkiye'de öğrenme stilleri konusunda yapılan tezlerin incelenmesi. Ĕ̆itim ve Öğretim Araştırmaları Dergisi, 4(3), 192-205.

Atılgan, D. (2018). Spor yönetiminde görev alan yöneticilerde kriz yönetimi, karar verme ve özgüven beceri düzeyleri arasındaki ilişkinin incelenmesi. Yayınlanmamış doktora tezi. Selçuk Üniversitesi, Sağlık Bilimleri Enstitüsü, Konya.

Aydın, A., Selvitopu, A., ve Kaya, M. (2018). Sınıf yönetimi alanındaki lisansüstü tezlerin incelenmesi. Abant İzzet Baysal Üniversitesi Eğitim Fakültesi Dergisi. 18(1), 41-56.

Ayna, Ü. H. (2019). Ortopedik ve görme engelli bireylerin özgüven düzeylerinin beden algıları açısından incelenmesi. Yayınlanmamış yüksek lisans tezi. Çukurova Üniversitesi, Sosyal Bilimler Enstitüsü, Adana.

Bandura, A. (1997). Self-efficacy: The exercise of control. New York: Freeman.

Başoğlu, T. S. (2007). Sınav kaygısı ile özgüven arasındaki ilişkinin erinlik döneminde incelenmesi. Yayınlanmamış yüksek lisans tezi. Maltepe Üniversitesi, Sosyal Bilimler Enstitüsü, İstanbul.

Beyazıt, U. (2015). Çocuk istismarı konusunda Türkiye'de yapılan lisansüstü tezlerin incelenmesi, Hacettepe Üniversitesi Sağ̆lk Bilimleri Fakültesi Dergisi, 1. Ulusal Sağlık Bilimleri Kongre Kitabı Özel Sayı, 1(1), 1-20.

Bilgin, O. (2017). Ergenlerin özgüven düzeyi ile yaşam amacı ve diğerleriyle olumlu ilişkiler arasındaki ilişki. Yaşadıkça Ĕ̆itim Dergisi, 31(2), 5566.

Can, Y., ve Kaçay, Z. (2016). Sporcu kimlik algisı ile cesaret ve özgüven duyguları arasındaki ilişkilerin incelenmesi. Journal of Human Sciences, 13(3), 6176-6184.

Cengiz, R., Arslan, F., ve Şahin, E. (2015). Beden eğitimi öğretmenlerinin özgüven ve boyun eğici davranışlarının incelenmesi. Turkish Journal of Education, 3(3), 4-10.

Ceylan, A. (2017). Ergenlerde mükemmeliyetçi benlik sunumunun özgüven ile ilişkisi. Yayınlanmamış yüksek lisans tezi. İstanbul Gelişim Üniversitesi Sosyal Bilimler Enstitüsü, İstanbul. 
Çevik, Z. (2015). Türkiye'de yaşayan yabancı uyruklu öğrenciler ile Türk uyruklu öğrencilerin özgüven düzeylerinin incelenmesi. Yayınlanmamış yüksek lisans tezi. Beykent Üniversitesi, Sosyal Bilimler Enstitüsü, İstanbul.

Değirmenci-Gündoğmuş, H. (2018). Okuduğunu anlama ile ilgili yapılan lisansüstü tezlerin incelenmesi. Electronic Turkish Studies, 13(2), 899910.

Doğru, Z. (2017). Beden eğitimi ve spor eğitimi bölümü öğrencilerinin özgüven ve özyeterlik algıları arasındaki ilişkinin değerlendirilmesi. Journal of Physical Education and Sports Studies, 9(1), 13-23.

Dursun, E. (2018). Çocukluk çă̆ında aile içerisinde şiddete maruz kalmış bireylerde özgüven ve öfke kontrol durumlarınn incelenmesi. Yayınlanmamış yüksek lisans tezi, İstanbul Gelişim Üniversitesi Sosyal Bilimler Enstitüsü, İstanbul.

Eldeleklioğlu, J. (2004). Çocuklarda özgüven gelişimi. Gazi Üniversitesi Eğitim Fakültesi Dergisi, 24(2), 111-121.

Erdem, D. (2011). Türkiye'de 2005-2006 yılları arasında yayımlanan eğitim bilimleri dergilerindeki makalelerin bazı özellikler açısından incelenmesi: Betimsel bir analiz. Eğitimde ve Psikolojide Ölçme ve Değerlendirme Dergisi, 2(1), 140-147.

Erpalabıyık, B (2018). Üniversite öğrencilerinin gençlik liderlik özellikleri ile benlik saygısı ve özgüven algılar arasındaki ilişkilerin incelenmesi, Yayınlanmamış Yüksek Lisans Tezi. Siirt Üniversitesi, Sosyal Bilimler Enstitüsü, Siirt.

Göknar, Ö. (2010). Özgüven kazanmak. 2. Baskı, Arkadaş Yayınevi: Ankara.

Güngören, Ö. C., Erdoğan, D. G., ve Ayas, T. (2018). Sanal zorbalık ile ilgili yapılmış lisansüstü tezlerin yapısal incelenmesi. Online Journal Of Technology Addiction \& Cyberbullying, 5(2), 1-20.

Güven, B., ve Özçelik, Ç. (2017). İlkokul matematik dersine yönelik gerçekleştirilen lisansüstü eğitim tez çalışmalarına ilişkin bir inceleme. Eğitimde Kuram ve Uygulama, 13(4), 693-714.

Hambly, K. (2003). Özgüven. (Çev. B. Bıçakçı), (5. Bsm), Alfa Yayınları: İstanbul.

Hildingh, C., Luepker R. V., Baigi A. and Lidell E. (2006). Stress, health complaints and self-confidence: A comprasion between young adult women in Sweden and USA, Scandinavian Journal of Caring Sciences, 20(2), 202-208. 
Humphreys, Tony (2002), Çocuk eğitiminin anahtarı: özgüven. (Çev. T. Anapa), (4. Bsm), İstanbul:Epsilon Yayınları.

Kapkın, B., Çalışkan, Z., ve Sağlam, M. (2018). Türkiye'de 1999-2017 yılları arasında değerler eğitimi alanında yapılmış lisansüstü çalışmaların incelenmesi. Değerler Eğitimi Dergisi, 16(35), 183-207.

Karadağ, E. (2009). Eğitim bilimleri alanında yapılmış doktora tezlerinin tematik açıdan incelemesi. Ahi Evran Üniversitesi Eğitim Fakültesi Dergisi, 10(3), 75-87.

Karamoy, K. Y., Wibowo, E. M. ve Jafar, M. (2018). The implementation of self-instruction and reframing group counselling techniques to improve students' self-confidence. Jurnal Bimbingan Konseling, 7 (1), 1-6.

Kasatura, İ. (1998). Kişilik ve özoüven. (Psikoloji Dizisi 4), İstanbul:Evrim Yayınevi.

Kocaarslan, B. (2009). Genel müzik eğitimi alan ilköğretim öğrencilerinin müzik dersine ilişkin tutum, müzikal özgüven ve motivasyon düzeylerinin karşılaştırılması. Yayınlanmamış Yüksek Lisans Tezi, Marmara Üniversitesi Eğitim Bilimleri Enstitüsü, İstanbul.

Koç, E. S. (2016). Türkiye de ilköğretim programlarının değerlendirilmesine yönelik yapılan lisansüstü tezlerin incelenmesi (2005-2014). Abant İzzet Baysal Üniversitesi Ĕ̆itim Fakültesi Dergisi. 16(1), 198-216.

Kurtoğlu, M., ve Seferoğlu, S. S. (2013). Öğretmenlerin teknoloji kullanımı ile ilgili Türkiye kaynaklı dergilerde yayımlanmış makalelerin incelenmesi. Öğretim Teknolojileri \& Öğretmen Eğitimi Dergisi, 2(3).

Lauster, P. (2010), Özgüven öğrenilebilir. (Çev. L. Yarbaş), (2. Bsm), İzmir:İlya Yayınevi.

Oktan, V. ve Şahin, M. (2010). Kız ergenlerde beden imajı ile benlik saygısı arasındaki ilişkinin incelenmesi. Uluslararası Insan Bilimleri Dergisi, 7 (2), 543-556.

Okyay, B. (2012). Yönetici ve çalışanların özgüven düzeyleri ve kişisel gelişim insiyatifi alma becerilerinin karşılaştırılması. Yayınlanmamış yüksek lisans tezi. Maltepe Üniversitesi, Sosyal Bilimler Enstitüsü, İstanbul.

Özbey, Ç. (2004). Çocuk sorunlarına yapıcı çözümler. İnkilap Kitabevi: İstanbul.

Parçal, F. K. (2018). Ergenlerin sosyal anksiyete düzeyleri ile özgüven algılarn arasındaki ilişkinin incelenmesi. Yayınlanmamış yüksek lisans tezi. Haliç Üniversitesi, Sosyal Bilimler Enstitüsü, İstanbul. 
Patır-Erkek, N. (2016). Yatılı ve gündüzlü eğitim alan ortä̈ğretim öğrencilerinin şiddet eğilimleri ile özgüvenleri arasındaki ilişkinin incelenmesi. Yayınlanmamış yüksek lisans tezi. Gazi Üniversitesi, Eğitim Bilimleri Enstitüsü, Ankara.

Püsküllüoğlu, E. I., ve Hoşgörür, V. (2017). Türkiye'de 2010-2016 yıllar1 arasında yapılan karşılaştırmalı eğitim lisansüstü tezlerinin değerlendirilmesi. Muğla Sıtkı Koçman Üniversitesi Eğitim Fakültesi Dergisi, 4(1), 46-61.

Sağat, H. (2016). Bireylerin anne baba tutumlarının özgüven ve sosyal fobiye olan ilişkisinin incelenmesi, Yayınlanmamış yüksek lisans tezi. İstanbul Bilim Üniversitesi, Sosyal Bilimler Enstitüsü, İstanbul.

Sarı, E. (2016). Çocuklarda özgüven gelişimi, Net Medya Yayıncılık: Antalya.

Seçer, İ., Ay, İ., Ozan, C., ve Yılmaz, Y. B. (2014). Rehberlik ve Psikolojik Danışma alanındaki araştırma eğilimleri: Bir içerik analizi. Türk Psikolojik Danışma ve Rehberlik Dergisi, 5(41), 49-60.

Soner, O. (1995). Aile uyumu, öğrenci özgüveni ve akademik başarı arasındaki ilişkiler. Yayınlanmamış doktora tezi. Marmara Üniversitesi, Sosyal Bilimler Enstitüsü, İstanbul.

Toktaş, S. (2017). Okul spor müsabakalarına katılan lise öğrencilerinin kaygı özgüven ve güdülemelerini arasındaki ilişkinin incelenmesi. Yayınlanmamış doktora tezi. Karadeniz Teknik Üniversitesi, Sosyal Bilimler Enstitüsü, Trabzon.

Tosun Sümer, E., ve Güven, M. (2018). Okul psikolojik danışmanlarıyla ilgili lisansüstü tezler üzerine bir inceleme. Journal of International Social Research, 11(60), 794-801.

Tosun, M. (2013). Din görevlilerinde olumsuz değerlendirme korkusu - özgüven ilişkisi:Afyonkarahisar örneği. Yayımlanmamış yüksek lisans tezi. Süleyman Demirel Üniversitesi, Sosyal Bilimler Enstitüsü, Isparta.

Umutlu, Ç. (2010). Çocuk dostu okul projesi kapsaminda olan ve olmayan ilköğretim okulu öğrencilerinin özgüvenleri ile zorbalık eğilimlerinin incelenmesi. Yayınlanmamış yüksek lisans tezi. Yeditepe Üniversitesi, Sosyal Bilimler Enstitüsü, İstanbul.

Yaşar, M. C. (2011). Türkiye'de okul öncesinde drama alanında yapılan lisansüstü tezlerin incelenmesi. Mehmet Akif Ersoy Üniversitesi Ĕ̆itim Fakültesi Dergisi, 1(22), 70-90. 
Yaşar, Ş., ve Papatğa, E. (2015). İlkokul matematik derslerine yönelik yapılan lisansüstü tezlerin incelenmesi. Trakya Üniversitesi Eğitim Fakültesi Dergisi, 5(2), 113-124.

\section{Kaynakça Bilgisi / Citation Information}

Bilgin, O. (2019). Türkiye'de özgüven ile ilgili yapılan lisansüstü tezlerin incelenmesi. OPUS-Uluslararası Toplum Araştırmaları Dergisi, 14(20), 371-393. DOI: 10.26466/opus.590461 